\title{
Morphology and molecular study of Fascioloides magna - a growing threat to cervids (Cervidae) in Poland
}

\author{
Marek Houszka ${ }^{1}$, Jolanta Piekarska², Magdalena Podkowik ${ }^{3}$, \\ Michał Gorczykowski ${ }^{2}$, Jacek Bania ${ }^{3}$ \\ ${ }^{1}$ Department of Pathology, \\ ${ }^{2}$ Department of Internal Medicine and Clinic of Diseases of Horses, Dogs, and Cats. Division of Parasitology, \\ ${ }^{3}$ Department of Food Hygiene and Consumer Health Protection, \\ Faculty of Veterinary Medicine, \\ Wroclaw University of Environmental and Life Sciences, 50-375 Wroclaw, Poland \\ jolanta.piekarska@up.wroc.pl
}

Received: August 2, $2016 \quad$ Accepted: November 16, 2016

\begin{abstract}
Introduction: The giant liver fluke, Fascioloides magna, has spread across Europe over the years posing a serious threat to the Polish cervid population. Material and Methods: Macroscopic and histopathological studies of the liver of 22 roe deer (Capreolus capreolus), 10 red deer (Cervus elaphus), and 6 fallow deer (Dama dama) were performed. Species determination of the recovered liver flukes and eggs was performed by PCR protocol amplifying fragments of ribosomal DNA (ITS2), according to a standard method. Results: The presence of $F$. magna was confirmed in three (13.6\%) roe deer, seven (70.0\%) red deer, and two (33.3\%) fallow deer. The fluke eggs were found only in the stools of five red deer and one fallow deer. Conclusion: This study presents detailed pathological and histopathological changes in the liver of wild Polish cervids, including roe deer, which were subjected to such study for the first time. The hepatic lesions typical for different stages of liver cirrhosis varied depending on the host species and stage of the disease.
\end{abstract}

Keywords: Cervidae, Fascioloides magna, liver, pathomorphology, PCR.

\section{Introduction}

Non-native wild game species, including the whitetailed deer (Odocoileus virginianus) and wapiti (Cervus elaphus canadensis), were introduced to Europe in the late nineteenth century (4). Some animals carried parasites and among them was Fascioloides magna, previously unknown on the continent. The liver fluke $F$. magna (Trematoda: Fasciolidae) is important in veterinary science and has a complex life cycle that includes intermediate snail hosts (Lymnaeidae) and definitive mammalian hosts (ungulates) (4). In Europe, the definitive host group includes roe deer (Cervus elaphus), red deer (Capreolus capreolus), and fallow deer (Dama dama) (16). There has been an increase in the number of infections by this parasite in Central Europe in recent years. The giant liver fluke has established three permanent natural foci: La Mandria Regional Park in northern Italy, the Danube floodplain forests, including Austria, Slovakia, Hungary, Croatia, and Serbia, and lastly the Czech Republic and southwestern Poland (7, 11, 12, 15, 18, 22). F. magna was first noted in red deer in Poland by Salomon in 1932 (19), followed by Ślusarski in 1953 (21). The infection was regional, affecting several parts of Silesia into which wapiti had previously been imported. The spread of this parasite among wild cervids (mainly roe and red deer) and in herds of farmed fallow deer is now encompassing larger areas of southern Poland (2, 3, 6 , 17). The study presented here indicates detailed pathological and histopathological changes in the liver of wild cervids, including roe deer in Poland, which were subjected to such study for the first time. Giant liver flukes are pathogenic for their hosts, causing extensive pathological changes in the liver. Migration of immature flukes in the liver tissue results in the creation of tunnels within the hepatic parenchyma, and the parasites' eggs may block bile ducts or stimulate the production of a pseudocyst, which may rupture the hepatic parenchyma via pressure atrophy (16). In roe deer, an infection with a few flukes may cause severe symptoms and may lead to 
death, even if these lesions are much smaller than in red deer (4). Coproscopic and post-mortem examinations in roe, red, and fallow deer indicate that $F$. magna is spreading to new areas of southern Poland and poses a real threat to the native cervid population. The aim of the study was to assess the nature and extent of lesions caused by the $F$. magna liver fluke in three species of wild cervid and to confirm this infection using coproscopic and molecular methods.

\section{Material and Methods}

The study was carried out on harvested roe deer, red deer, and fallow deer from the southwest part of Poland (Lower Silesia, Jawor) and the Lubusz region (Nowogród Bobrzański) (Fig. 1). The animals were shot as part of a programme controlling the deer population and their livers were submitted to the Laboratory of Ecology and Diseases of Game at the University of Environmental and Life Sciences in Wroclaw. The liver of 38 wild cervids ( 22 roe deer, 10 red deer, and 6 fallow deer) was assessed. Liver samples were fixed in $8 \%$ buffered formalin, and 4 $\mu \mathrm{m}$ thick paraffin sections were stained with haematoxylin and eosin. Parasitological examination of faecal samples from the recta of 19 roe deer, 9 red deer, and 1 fallow deer were also performed. Decantation according to the method of Żarnowski and Josztowa (24) was performed on three grams of stool to evaluate the presence of parasite eggs. Parasites removed from the liver were examined macroscopically and with the use of a stereo microscope (magnification 10-20×). Liver flukes were preserved in $75 \%$ ethyl alcohol. Species determination of the recovered flukes was performed by PCR protocol amplifying fragments of ribosomal DNA (ITS2), according to a standard method. Universal and species-specific primers designed for $F$. magna and $F$. hepatica were used in molecular studies $(1,10)$ and are described in Tables 1 and 2. The genomic DNA was isolated from $20 \mathrm{mg}$ of adult $F$. magna tissue obtained from parenchymatous liver cysts, 30 eggs of F. magna fixed in $75 \%$ ethanol, and $20 \mathrm{mg}$ of a homogenised liver sample using the GeneMATRIX Tissue DNA Purification Kit (EURx,
Poland) according to the manufacturer's recommendations. It was later diluted in $50 \mu \mathrm{L}$ of deionised water and stored at $-20^{\circ} \mathrm{C}$. The conditions necessary to perform the reaction using species-specific primers are presented in Table 3. The obtained PCR products were sequenced (Genomed, Poland), and the sequence was assessed using the BLAST Sequence Analysis Tool (http://blast.ncbi.nlm.nih.gov).

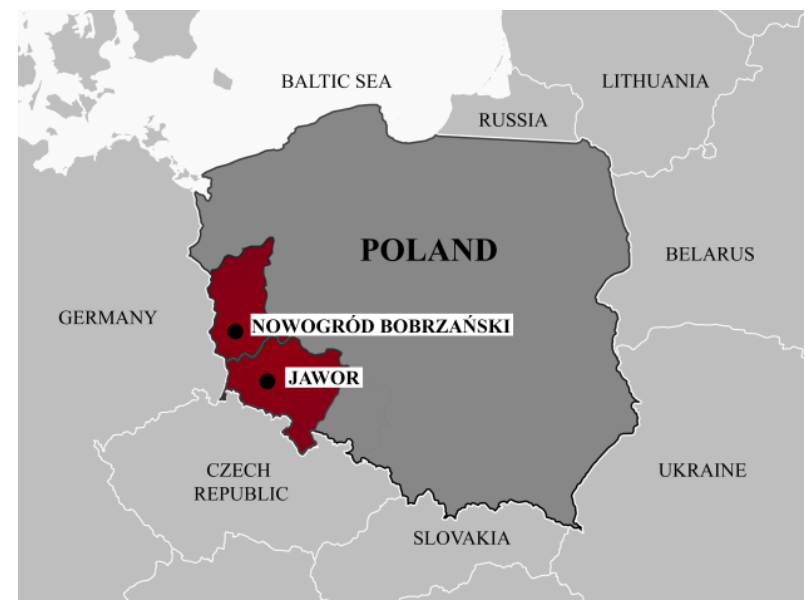

Fig. 1. Distribution of $F$. magna in Poland - the study region

Table 1. Species-specific primers used to identify Fasciola hepatica (FH) and Fascioloides magna (FM) and targeted to amplify ribosomal ITS2 (10)

\begin{tabular}{lc}
\hline \multicolumn{1}{c}{ Sequence } & PCR product size \\
\hline FH_ITS_SPEC_F & \\
5'-CTTATGATTTCTGGGATAATT-3' & $112 \mathrm{bp}$ \\
FH_ITS_SPEC_R & \\
5'-CCGTCGCTATATGAAAA-3' & \\
FM_ITS_SPEC_F & $152 \mathrm{bp}$ \\
5'-ACCAGTTATCGTTGTGTTG-3' & \\
FM_ITS_SPEC_R & \\
5'-CCGTCTTTAAACAACAG-3' & \\
\hline
\end{tabular}

Table 2. Universal primers designed for $F$. magna and $F$. hepatica used to amplify ribosomal ITS2 and targeted to develop the sequenced product

\begin{tabular}{lc}
\hline \multicolumn{1}{c}{ Sequence } & $\begin{array}{c}\text { PCR product } \\
\text { size }\end{array}$ \\
\hline FAS_uni1 & \\
5'-CTATCACGACGCCCAAAAAGTCGT-3' & $358 \mathrm{bp}$ \\
FAS_uni2 & \\
5'-GAAGACTGATCACGAAGGATACC-3' & \\
\hline
\end{tabular}

Table 3. PCR conditions when using species-specific and universal primers

\begin{tabular}{llll}
\hline & & Species-specific primers & Universal primers \\
\hline Initial denaturation & & $94^{\circ} \mathrm{C} / 5 \mathrm{~min}$ & $94^{\circ} \mathrm{C} / 3 \mathrm{~min}$ \\
\hline \multirow{3}{*}{ Amplification } & denaturation & $94^{\circ} \mathrm{C} / 1 \mathrm{~min}$ & $94^{\circ} \mathrm{C} / 30 \mathrm{~s}$ \\
& annealing & $51^{\circ} \mathrm{C} / 1 \mathrm{~min}$ & $54^{\circ} \mathrm{C} / 30 \mathrm{~s}$ \\
& elongation & $72^{\circ} \mathrm{C} / 2 \mathrm{~min}$ & $72^{\circ} \mathrm{C} / 30 \mathrm{~s}$ \\
\hline Number of cycles & & 30 & 30 \\
\hline
\end{tabular}

Table 4. Intensity of hepatic lesions and the presence of parasite eggs

\begin{tabular}{|c|c|c|c|c|c|c|c|}
\hline \multirow{3}{*}{ Species } & \multirow{3}{*}{$\begin{array}{c}\text { Number of } \\
\text { tested } \\
\text { samples }\end{array}$} & \multirow{3}{*}{$\begin{array}{l}\text { Number of } \\
\text { samples with } \\
\text { flukes }\end{array}$} & \multicolumn{3}{|c|}{ Liver } & \multicolumn{2}{|c|}{ Stool } \\
\hline & & & & sity of the le & & \multirow{2}{*}{$\begin{array}{l}\text { Number of } \\
\text { tested } \\
\text { samples }\end{array}$} & \multirow{2}{*}{$\begin{array}{c}\text { Number of } \\
\text { samples with } \\
\text { eggs of } \\
\text { F. magna }\end{array}$} \\
\hline & & & severe & mild & none & & \\
\hline Roe deer & 22 & $3(13.6 \%)$ & $8(36.4 \%)$ & $7(31.8 \%)$ & $7(31.8 \%)$ & 19 & - \\
\hline Red deer & 10 & $7(70.0 \%)$ & $8(80.0 \%)$ & $2(20.0 \%)$ & $0(0 \%)$ & 8 & 5 \\
\hline Fallow deer & 6 & $2(33.3 \%)$ & $3(50.0 \%)$ & $2(33.3 \%)$ & $1(16.7 \%)$ & 1 & 1 \\
\hline
\end{tabular}




\section{Results}

Out of 22 roe deer, 10 red deer, and 6 fallow deer livers, the presence of flukes was confirmed in three $(13.6 \%)$, seven $(70.0 \%)$, and two $(33.3 \%)$ respectively. Hepatic lesions varied depending on the host species and stage of the disease. Extensive hepatic changes covering the whole organ were described as severe but localised mild hepatic lesions were also observed (Table 4). Perforations and milk spots were visible on the capsular surface of the liver at an early stage of the infection and indicated the site of liver penetration by the migrating flukes (Fig. 2). The migration of young flukes through the liver parenchyma caused the formation of dark-brown irregular linear depressions particularly visible in roe deer. These were the remnants of organised small tunnels (Fig. 3). As the flukes grew, they created increasingly larger migratory tunnels of up to $1-3 \mathrm{~cm}$ in diameter, which were filled with blood or dark brown clots (due to the presence of haematin). Secondary bacterial infections occurred in some of the animals and necrotic foci of various sizes were formed. These were yellowish in colour or were filled with blood and haematin. The advancing fibrosis led to the development of various liver deformations and scarring. Fibrin was present in small amounts on the liver capsule of the roe deer. In the red deer and fallow deer, large areas of the liver capsule were coated with fibrin of a jagged or filamentous structure, which formed adhesions between the liver and the surface of the diaphragm. From one to four cystic structures located superficially, $6-8 \mathrm{~cm}$ large, consisting of a 2-3 mm thick wall and filled with a dark brown fluid were also found, particularly in fallow deer. Adult flukes were present in the migratory tunnels and cysts (Fig. 4). In red deer liver, from under ten to several dozen flukes were found, which ranged in size from 6 to $9 \mathrm{~cm}$. The fluke infections were less marked in fallow deer. In roe deer, on the other hand, cysts containing three to four adult flukes were found sporadically. They were found in 2 out of the 6 examined fallow deer and 3 out of the 22 roe deer. In advanced stages of infection, bloody, serous, darkbrown exudate was present in the peritoneal cavity, which stained the omentum and other organs. The walls of the migratory tunnels underwent gradual organisation as they transformed into fibrous connective tissue with deposits of haematin of various sizes, visible in the microscopic examination (Fig. 5). Lymphocytic and histiocytic infiltrates were present in certain areas and indicated local inflammation. The peripheral bile ducts were proliferated. The lumen of the tunnel decreased or was divided by the growing connective tissue leading to the formation of numerous fissures. The walls of the large cystic formations had a similar structure, although they were much thicker, indicating collagenisation. These cystic structures were most likely local expansions of the migratory tunnels.
Fluke eggs were present in cysts as well as in the tunnel fissures.

Using the sedimentation method, fluke eggs were found in the stools of five red deer and one fallow deer. They were not found in those of any roe deer (Table 4). An F. magna infection was also confirmed using PCR with DNA isolated from adult fluke, fluke eggs, and liver homogenate (Fig. 6), while the BLAST Sequence Analysis Tool confirmed the obtained sequences. None of the tested animals had an F. hepatica infection, which nevertheless does occur naturally in Polish ruminants.

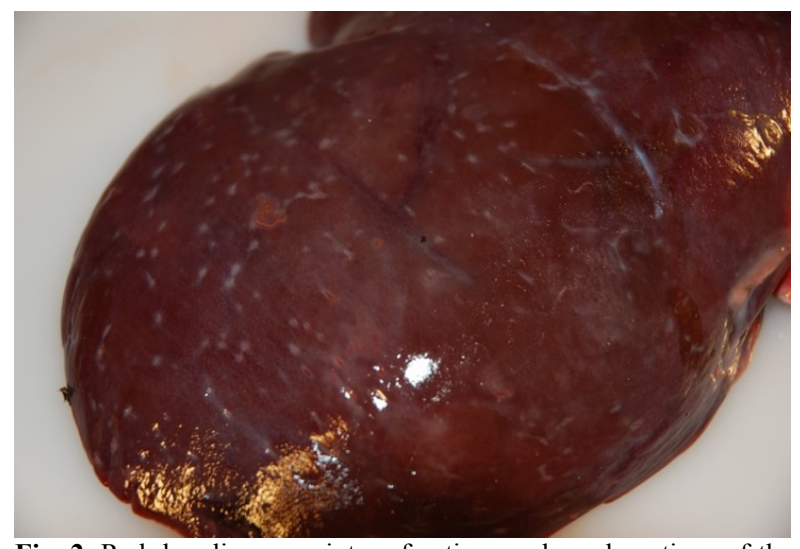

Fig. 2. Red deer liver - point perforations and condensations of the capsule indicate the migratory route of the juvenile flukes in the digestive tract and liver

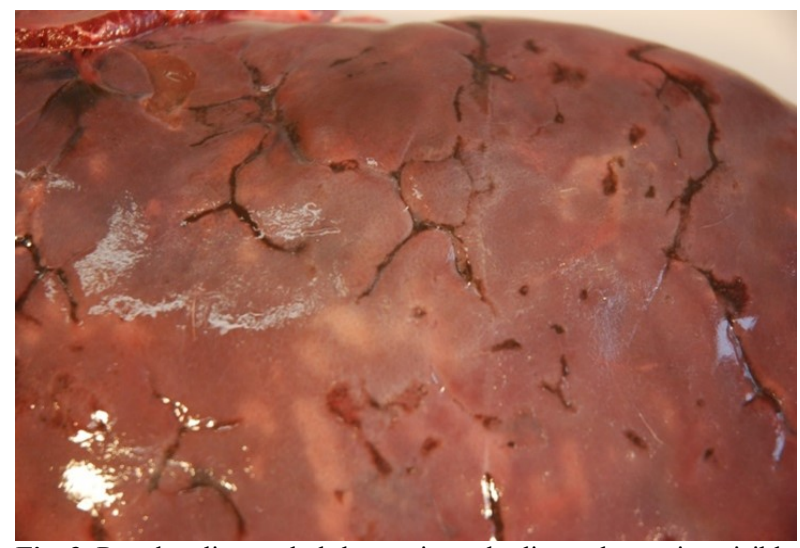

Fig. 3. Roe deer liver - dark-brown irregular linear depression visible on the surface of the organ

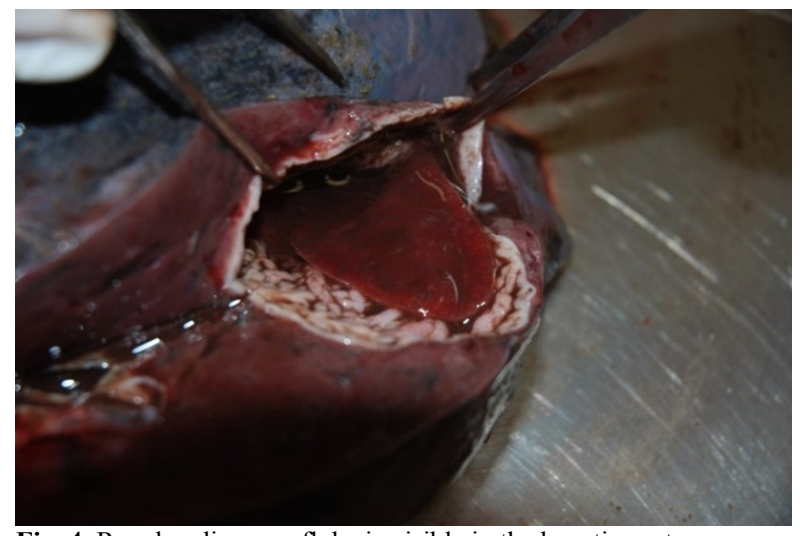

Fig. 4. Roe deer liver - a fluke is visible in the hepatic cyst 


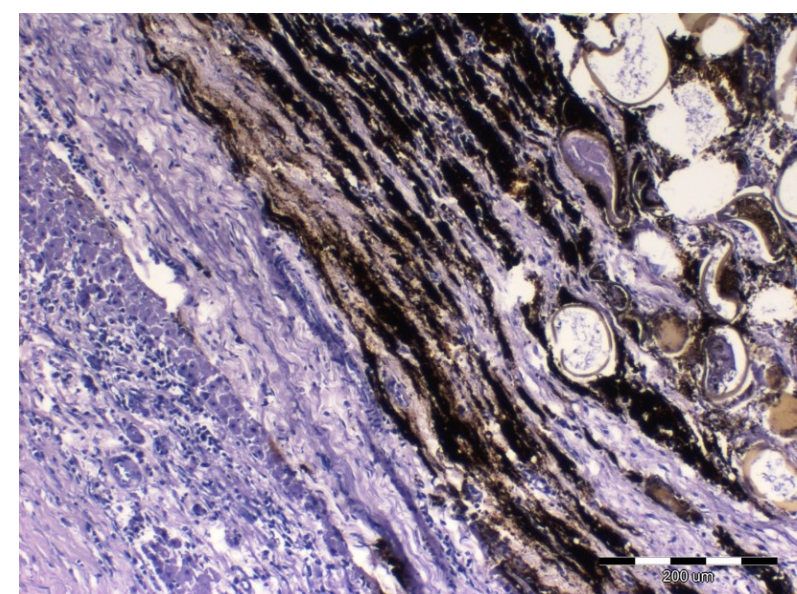

Fig. 5. Red deer liver - a fibrotic wall of the liver tunnel filled with haematin created by a migrating fluke. Numerous fluke eggs are visible in the lumen of the tunnel

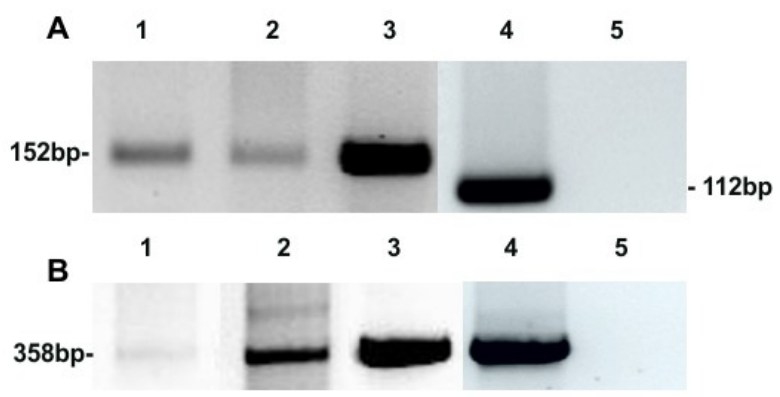

Fig. 6. An electrophoresis image showing the obtained PCR products using (A) - specific $F$. magna primers and (B) - universal FAS primers for $F$. magna and $F$. hepatica. 1 - homogenised liver sample, 2 - eggs, 3 - adult $F$. magna, 4 - adult $F$. hepatica, 5 - negative control

\section{Discussion}

Observations carried out in numerous European countries indicate a spread of $F$. magna infection in cervids. In Croatia, over $50 \%$ of the red deer population is affected by this fluke (18). In the Czech Republic, in some areas, up to $95 \%$ of deer suffer from an $F$. magna infection (14) and $20-100 \%$ of red deer are affected in the single infected population east of Vienna in Austria $(20,22)$. A fluke infection is commonly diagnosed using faecal examination (the decantation method). However, the diagnosis is quite difficult as $F$. magna eggs have a similar appearance to those of $F$. hepatica. Therefore, the authors of this study decided to use a molecular method to differentiate these two flukes. Environmental factors play a key role in the prevalence and intensity of the fluke infection (23) and are more important in its development than the density of the animal population (12). On the one hand, the most dangerous areas for wild game are floodplain and swamp habitats since infections are usually limited to these territories. On the other hand, most hunting grounds contain single or multiple wetlands where flukes can multiply. In one of the studied hunting grounds where wetlands accounted for less than $10 \%$ of the total area, there was a mass fluke infection and a significant decrease in the roe deer population (23). Another factor which contributes to the spread of the infection is the tendency of deer to cover long distances and disseminate fluke eggs (16). Obviously, the role of snails infected with developing larval stages, which migrate along watercourses transmitting infections has been underestimated. The Danube River was found to be a primary transmission route of this fluke species in Europe. Molecular studies have shown that the Czech fluke haplotype is convergent with that found in other Danube countries, suggesting the parasite was transported from the Czech Republic to Hungary, Austria, and Croatia (9, 20). Further studies in the Czech Republic have shown the spread of $F$. magna foci not only in the south-western parts of the country but also in the west, near the German border and in the north, near the Polish border (7). Recent molecular research on giant liver fluke specimens from southwestern Poland based on mitochondrial markers (cox1 and nad1) revealed the genetic uniformity of $F$. magna specimens from Poland with certain specimens from a Czech natural focus (8). The outbreak area which we identified is located near Nowogród Bobrzański, which, in turn, is situated roughly $60 \mathrm{~km}$ from Bolesławiec, where the occurrence of $F$. magna was first described by Salomon in 1932 (19) and Ślusarski in 1955 (21). The Bóbr and Kwisa rivers, which pass through Bolesławiec, flow to Nowogród. Hence, the F. magna fluke was most likely primarily transmitted through that route. In recent years the introduction of cervids across Poland, particularly the fallow deer, may also play an important role in the transmission of the $F$. magna fluke. The number of fallow deer farms is growing rapidly, and rearing conditions may contribute to parasite infections (6). Fallow deer are eagerly bought by hunters and placed in open hunting grounds, where their parasite fauna is released into the environment, leading to further sources of infection.

The gross and histopathological examinations reveal typical lesions for different stages of liver cirrhosis. However, fluke development was blocked in the roe deer at an early stage of migration, while in fallow deer, the same as in Karamon et al. (6), and in red deer, the same as in Demiaszkiewicz et al. (3), it was followed by the formation of cysts with adult flukes and by egg production. The stool analysis of 19 studied roe deer did not indicate the presence of fluke eggs, despite substantial changes in the liver of some of these animals. Therefore, red deer and fallow deer are the only species which are responsible for spreading this parasite in Poland. Despite this, infection of $F$. magna usually leads to severe clinical changes in roe deer. It is remarkable that despite a considerable burden of infection with over $100 \mathrm{~F}$. magna flukes per individual possible, the European red deer and fallow deer do not usually show any clinical signs or even moderate decline in their condition $(13,16)$. In roe deer, infection with a few flukes may cause severe 
symptoms and may lead to death, even if these lesions are much smaller than in red deer (4). This leads to the suggestion that the cause of death of these animals is not so much damage and dysfunction of the liver, but an uncontrolled immune response to the presence of the fluke. We found that only adult deer were infected with $F$. magna fluke. No lesions were present in the liver of deer calves, nor were there any fluke eggs present in their stool. This is presumably due to the fact that young deer suckle milk until winter and ingest smaller amounts of more delicate and drier plants than adult animals. In winter, most of the metacercariae die, and it is not until spring that the intermediate snail hosts are infected, which leads to a mass emergence of metacercariae within two to three months (5). It is worth noting that none of the tested animals had an $F$. hepatica infection, which is known to occur naturally in Polish ruminants. Even the smallest isolated flukes showed morphological and molecular characteristics of juvenile forms of $F$. magna. This may suggest that in some areas, a new, dynamic species of the American fluke has replaced the endemic F. hepatica.

Conflict of Interests Statement: The authors declare that there is no conflict of interests regarding the publication of this article.

Financial Disclosure Statements: This research was supported by statutory research and development activity funds assigned to the Faculty of Veterinary Medicine, Wroclaw University of Environmental and Life Sciences. Editorial corrections were supported by the Wroclaw Centre of Biotechnology, within the Leading National Research Centre (KNOW) programme for the years 2014-2018.

Animal Rights Statement: None required.

\section{References}

1. Bazsalovicsova E., Kralova-Hromadova I., Spakulova M., Reblanova M., Oberhauserova K.: Determination of ribosomal internal transcribed spacer 2 (ITS2) in terspecific markers in Fasciola hepatica, Fascioloides magna, Dicrocoelium dendriticum and Paramphistomum cervi (Trematoda), parasites of wild and domestic ruminants. Helminthologia 2010, 47, 76-82.

2. Demiaszkiewicz A.W., Kuligowska I., Pyziel A.M., Lachowicz J., Kowalczyk R.: Extension of occurrence area of the American fluke Fascioloides magna in south-western Poland. Ann Parasitol 2015, 61, 93-96.

3. Demiaszkiewicz A.W., Pyziel A.M., Kuligowska I., Lachowicz J.: Fascioloides magna a parasite of red deer in Lower Silesian Wilderness. Med Weter 2016, 72, 110-112.

4. Erhardová-Kotrlá B.: The occurrence of Fascioloides magna (Bassi, 1875) in Czechoslovakia, Academia Prague, 1971, p. 155.

5. Haider M., Hörweg C., Liesinger K., Sattmann H., Walochnik J.: Recovery of Fascioloides magna (Digenea) population in spite of treatment programme? Screening of Galba truncatula (Gastropoda, Lymnaeidae) from Lower Austria. Vet Parasitol 2012, 187, 445-451.

6. Karamon J., Larska M., Jasik A., Sell B.: First report of the giant liver fluke (Fascioloides magna) infection in farmed fallow deer
(Dama dama) in Poland - pathomorphological changes and molecular identification. Bull Vet Inst Pulawy 2015, 59, 339-344.

7. Kasny M., Beran L., Siegelova V., Siegel T., Leontovyc R., Berankova K., Pankrac J., Kostakova M., Horak P.: Geographical distribution of the giant liver fluke (Fascioloides magna) in the Czech Republic and potential risk of its further spread. Vet Med Czech 2012, 57, 101-109.

8. Králová-Hromadová I., Bazsalovicsová E., Demiaszkiewicz A.W.: Molecular characterization of Fascioloides magna (Trematoda: Fasciolidae) from south-western Poland based on mitochondrial markers. Acta Parasitol 2015, 60, 544-547.

9. Kralova-Hromadova I., Bazsalovicsova E., Stefka J., Spakulova M., Vavrova S., Szemes T., Tkach V., Pybus M.: Multiple origins of European populations of the giant liver fluke Fascioloides magna (Trematoda: Fasciolidae), a liver parasite of ruminants. Int J Parasitol 2011, 41, 373-383.

10. Kralova-Hromadova I., Špakulova M., Horackova E., Turcekova L., Novobilsky A., Beck R., Koudela B., Marinculić A., Rajský D., Pybus M.: Sequence analysis of ribosomal and mitochondrial genes of the giant liver fluke Fascioloides magna (Trematoda: Fasciolidae): intraspecific variation and differentiation from Fasciola hepatica. J Parasitol 2008, 94, 58-67.

11. Majoros G., Sztojkov V.: Appearance of the large American liver fluke Fascioloides magna (Bassi, 1875) (Trematoda: Fasciolata) in Hungary. Parasitol Hung 1994, 27, 27-38.

12. Malcicka M.: Life history and biology of Fascioloides magna (Trematoda) and its native and exotic hosts. Ecol Evol 2015, 5, 1381-1397.

13. Marinkovic D., Kukolj V., Aleksic-Kovacevic S., Jovanovic M., Knezevic M.: The role of hepatic myofibroblasts in liver cirrhosis in fallow deer (Dama dama) naturally infected with giant liver fluke (Fascioloides magna). BMC Vet Res 2013, 9, 45.

14. Novobilský A., Horackova E., Hirtova L., Modry D., Koudela B.: The giant liver fluke Fascioloides magna (Bassi, 1875) in cervids in the Czech Republic and potential of its spreading to Germany. Parasitol Res 2007, 100, 549-553.

15. Plötz C., Rehbein S., Bamler H., Reindl H., Pfister K., Scheuerle M.C.: Fascioloides magna - epizootiology in a deer farm in Germany. Berl Münch Tierärztl Wochenschr 2015, 128, 177-182.

16. Pybus M.J.: Liver flukes. In: Parasitic diseases of wild mammals, edited by Samuel W.M., Pybus M.J., Kocan A.A. Iowa State Press, Iowa City, 2001, pp. 121-149.

17. Pyziel A.M., Demiaszkiewicz A.W., Kuligowska I.: Molecular identification of Fascioloides magna (Bassi, 1875) from red deer from South-Western Poland (Lower Silesian Wilderness) on the basis of internal transcribed spacer 2 (ITS-2). Pol J Vet Sci 2014, 17, 523-525.

18. Rajkovic-Janje R., Bosnić S., Rimac D., Gojmerac T.: The prevalence of American liver fluke Fascioloides magna (Bassi 1875) in red deer from Croatian hunting grounds. Eur J Wildl Res 2008, 54, 525-528.

19. Salomon S.: Fascioloides magna bei deutschem Rotwild. Berl Tierärztl Wochenschr 1932, 48, 627-628.

20. Sattmann H., Horweg C., Gaub L., Feix A.S., Haider M., Walochnik J., Rabitsch W., Prosl H.: Wherefrom and whereabouts of an alien: the American liver fluke Fascioloides magna in Austria: an overview. Wien Klin Wochenschr 2014, 126, 23-31.

21. Ślusarski W.: Studies on the European representatives of the fluke Fasciola magna (Bassi, 1875) Stiles, 1894: a new case of the fluke invasion in stag in Silesia (Poland). Acta Parasitol Pol 1955, 3, 1-59.

22. Ursprung J., Joachim A., Prosl H.: Epidemiology and control of the giant liver fluke, Fascioloides magna, in a population of wild ungulates in the Danubian wetlands east of Vienna. Ber Münch Tierärztl 2006, 119, 316-323.

23. Vanderwaal K.L., Windels S.K., Olson B.T., Vannatta J.T., Moen R.: Landscape influence on spatial patterns of meningeal worm and liver fluke infection in white-tailed deer. Parasitology 2015, 142, 706-718.

24. Ziomko I., Cencek T.: Outline of laboratory diagnostic of farm animal parasites. Ed. National Veterinary Research Institute, Pulawy, Poland, 1995. 